\title{
Vitamin A Deficiency is Still a Public Health Problem in India
}

\author{
NARLAPPA \\ Scientist 'D', Division of Community Studies, National Institute of Nutrition, (Indian Council of Medical Research), \\ Jamai-Osmania PO, Hyderabad 500 007,Andhra Pradesh,India.arlappan@yahoo.com
}

A pproximately one third of the world's preschool-age population is estimated to be vitamin A deficient; with highest prevalence (44-50\%) being reported in regions of Africa and South-East Asia [1].Vitamin A deficiency continues to be a major public health nutritional problem in India. The prevalence of Bitot's spot, the objective sign of clinical VAD $(0.8 \%)$ was higher than the figures recommended by the WHO $(\geq 0.5 \%)$, indicating the public health significance in rural pre-school children of India [2]. While in case of blood vitamin A deficiency $(<20 \mu \mathrm{g} / \mathrm{dL})$, the prevalence $(61 \%)$ was a severe public health problem $(\geq 20 \%)$ [4] in all NNMB states, ranging from $52 \%$ in Maharashtra to $88 \%$ in Madhya Pradesh. The proportion of severe blood $\operatorname{VAD}(<10 \mu \mathrm{g} / \mathrm{dL})$ was $(21.5 \%)$ also $\geq 5 \%$, indicating severe public health problem [3] in all the National Nutrition Monitoring Bureau (NNMB) states [4].

In this issue of Indian Pediatrics, Sachdeva, et al. reported the prevalence of clinical VAD and various determining factors associated with the high prevalence of VAD (9.1\%) among pre-school children of Aligarh district, Uttar Pradesh [5]. This study reported the prevalence of Bitot's spots as $5.4 \%$ and night blindness as $2.8 \%$, both higher than the WHO cut-off levels, indicating significant public health concern. This study reported the lower social status and mother's illiteracy for high prevalence of VAD among children, which is in accordance with earlier studies in India [6,7]. This article also reported that dietary factors are the major determinants of VAD. NNMB study also reported similar observation i.e. the diets of rural pre-school children in India were grossly deficient in vitamin $\mathrm{A}$, where the median intakes were deficient by $66-81 \%$ as against the RDA of $400 \mu \mathrm{g}$ and about $84 \%$ of pre-school children were not even meeting $50 \%$ of their RDA [8].

This article also reported high prevalence of severe forms of clinical VAD such as corneal ulceration and corneal scar. This re-emergence of severe forms of $\mathrm{VAD}$ is alarming and challenges the commonly held opinion of many nutritionists and public health personnel who believe that VAD has declined considerably in India, as none of the earlier studies including NNMB reported severe forms of VAD. This article also reveals that the prevalence of clinical VAD is on rise, in contrast to NNMB and other studies, which reported persistent reduction in clinical VAD over a period. The article could have contained the operational definition of corneal ulceration and corneal scar in the methodology, because the prevalence was unusually high and the same may be contributed by injuries and infections.

This article has few errors, which needs to be rectified/explained. It is not clear which variable is taken as reference and which variable is at risk in Tables. In this case, calculation of proportion for each variable is more appropriate than Odd's ratios. The authors reported the prevalence of underweight, stunting and wasting as $32 \%, 65 \%$ and $72 \%$, respectively among children of Aligarh district, Uttar Pradesh. However, if we calculate carefully, the actual prevalence of underweight was $67.9 \%$, while the proportion of stunting and wasting was $35 \%$ and $27.6 \%$, respectively. Also, if we calculate prevalence of xerophthalmia with the existing figures, the prevalence would be $70 \%$ among children of working 
mothers and $37.3 \%$ in children of working mothers. Since there is a serious error either in analysis or typing, the authors need to rectify these errors. The authors mentioned in the discussion, that mother's literacy has positive impact on VAD; however, if we calculate carefully, the prevalence is more in children of literate mothers $(6.1 \%)$ compared to illiterate mothers $(0.8 \%)$. Authors reported a significant association between wasting and xerophthalmia; however, similar association is observed with stunting also.

\section{REFERENCES}

1. World Health Organization (WHO). Global prevalence of vitamin A deficiency in populations at risk 1995-2005. WHO Global Database on Vitamin A Deficiency. Geneva: WHO;2009.

2. National Nutrition Monitoring Bureau (NNMB). Prevalence of Micronutrient deficiencies. Hyderabad, India: National Institute of Nutrition; 2003.
3. World Health Organization (WHO). Indicators for assessing Vitamin A deficiency and their application in monitoring and evaluating intervention programmes. Geneva: WHO;1996.

4. National Nutrition Monitoring Bureau (NNMB). Prevalence of vitamin A deficiency among rural pre-school children. Hyderabad: National Institute of Nutrition: 2006.

5. Sachdeva S, Alam S, Beig FK, Khan Z, Khalique N. Determinants of vitamin A deficiency amongst children in Aligarh district, Uttar Pradesh. Indian Pediatr. 2011; 48:861-66.

6. Arlappa N, Balakrishna N, Laxmaiah A, Raghu P, Vikas, Nair KM, Brahmam GNV. Prevalence of vitamin A deficiency and its determinants among rural pre-school children of Madhya Pradesh, India. Ann Hum Biol. 2011;38:131-6.

7. Arlappa N, Venkaiah K, Brahmam GNV. Severe drought and the vitamin A status of rural pre-school children in India. Disasters. 2011; 35:577-86.

8. National Nutrition Monitoring Bureau (NNMB). Diet and Nutritional status of population and prevalence of hypertension among adults in rural areas. Hyderabad: National Institute of Nutrition; 2006. 